\title{
Irish school children's knowledge of the origins of their breakfast foods
}

\author{
G.H.F. Liu ${ }^{1}$, S. Speidel ${ }^{1}$, C.A. Corish ${ }^{1}$ and K. McAdoo ${ }^{2}$ \\ ${ }^{1}$ School of Public Health, Physiotherapy and Sports Science, University College Dublin, Dublin, Ireland and \\ ${ }^{2}$ Airfield Estate, Overend Way, Dundrum, Ireland
}

Understanding the origin of food can help children make informed food choices ${ }^{(1)}$. Regular breakfast consumption is positively associated with health benefits for children and adolescents ${ }^{(2)}$. The aim of this study was to explore children's knowledge of the origin of their food with an emphasis on breakfast consumption.

The frequency of breakfast consumption, attitudes to breakfast and knowledge about the origin of foods commonly eaten at breakfast were investigated in urban-dwelling pupils from primary school $(n, 213)$ and secondary school junior cycle $(n, 137)$ who were participating in a school-organised farm visit using a nine-question, multiple-choice, study-specific questionnaire administered just before the farm visit. Responses were indicated by pupils raising their hands to their answer of choice. To minimise response bias, pupils kept their eyes closed throughout.

The majority $(80 \%)$ of school pupils consumed breakfast daily. This was significantly higher in the younger primary school pupils compared with those in junior cycle secondary school ( $85 \%$ vs. $53 \%$, respectively). Breakfast consumption did not differ by gender $(73 \%$ vs. $81 \%$ p > 0.05). Sixty-percent of children correctly identified animal products consumed at breakfast but their knowledge about the animal origin of these foods was poor (average score $45 \%$ ) with no gender differences observed. As expected, the junior cycle pupils had better knowledge about the origin of foods than the primary school pupils $(58 \% v s .37 \%$, respectively; $\mathrm{p}<0.05)$. Table 1 demonstrates the overall results of the survey.

Table 1. Food origin knowledge of urban-dwelling school children $(n=350)$.

\begin{tabular}{lccc}
\hline & \multicolumn{3}{c}{ Possible Responses } \\
\cline { 2 - 4 } Knowledge Questions & $\begin{array}{c}\text { Correct } \\
\%(\mathrm{n})\end{array}$ & $\begin{array}{c}\text { Incorrect } \\
\%(\mathrm{n})\end{array}$ & $\begin{array}{c}\text { Unsure } \\
\%(\mathrm{n})\end{array}$ \\
\hline The following food items contain animal products: & & \\
1. Porridge & $40(141)$ & $26(90)$ & $34(119)$ \\
2. Cheese Omelette & $72(252)$ & $8(27)$ & $20(71)$ \\
3. Baked Beans & $60(210)$ & $4(15)$ & $36(125)$ \\
4. White Pudding & $59(205)$ & $10(36)$ & $31(106)$ \\
5. Honey & $46(159)$ & $32(112)$ & $22(77)$ \\
Food origins of the following items: & & & \\
6. Porridge & $25(89)$ & $67(234)$ & $8(28)$ \\
7. Milk & $49(172)$ & $48(170)$ & $3(9)$ \\
8. Cheese & $48(166)$ & $45(158)$ & $7(25)$ \\
9. White Pudding & $10(35)$ & $57(198)$ & $33(117)$ \\
\end{tabular}

Urban-dwelling school pupils have a basic understanding about where foods consumed at breakfast originate. In relation to animal products, knowledge of their animal of origin is poor. Breakfast skipping, associated with poor food choices during the day and childhood overweight/obesity ${ }^{(3)}$, is frequent in older school pupils. As farm-based educational programmes enhance children's knowledge about food ${ }^{(4)}$, they could potentially improve Irish urban-dwelling children's food choice, their decision-making and improve their diet-related behaviours.

1. Vidgen HA, Gallegos D (2014) Appetite 76, 50-59.

2. Rampersaud GC, Pereira MA, Girard BL et al. (2005) J Am Diet Assoc 105, 743-760.

3. Abarca-Gómez L, Abdeen ZA, Hamid ZA et al. (2017) Lancet 390, 2627-2642.

4. Kos M, Jerman J. (2012) Nutr \& Food Sci. 42, 324-31. 